\title{
"I am mostly concerned about their education": Syrian refugee families and the right to education in Lebanon
}

\author{
Bree Akesson \\ Associate Professor \\ Wilfrid Laurier University \\ bakesson@wlu.ca \\ Dena Badawi \\ Research Assistant \\ Wilfrid Laurier University \\ denabadawi10@gmail.com \\ Abdelfettah Elkchirid \\ Associate Professor \\ Wilfrid Laurier University \\ aelkchirid@wlu.ca
}

\begin{abstract}
Ongoing since 2011, the conflict in Syria is considered to be one of the largest humanitarian crises in modern history. With a large number of Syrian families fleeing the war to resettle in neighboring Lebanon, Lebanon's education system has become overwhelmed. In this paper, we will describe how Syrian families and community stakeholders experienced education in Lebanon and highlight barriers to education, suggesting potential interventions to ensure that the right to education is upheld. The findings underscore the multiple challenges that Syrian families face in seeking education for their children. At the same time, the findings point to the importance of education in the lives of Syrian families both in Syria before the war, in their current contexts of displacement in Lebanon, and in their future hopes and dreams for their children.
\end{abstract}

Keywords: Syria, refugee, family, children, education, displacement, resettlement, child rights, political violence 


\section{Introduction}

Nearly a decade has passed since the beginning of the conflict in Syria. This conflict has become one of the largest humanitarian crises in modern history (Government of Lebanon (GoL) \& United Nations (UN), 2020). In that time, over 5.5 million refugees from Syria have fled to the neighboring countries of Iraq, Jordan, Lebanon, and Turkey (United Nations High Commissioner for Refugees (UNHCR), 2020). Lebanon is host to over one million Syrian refugees, the country with the largest Syrian refugee population per capita (GoL \& UN, 2020; Kelley, 2017). Of those, over $50 \%$ of Syrian refugees in Lebanon are children under the age of 18 whose lives have been uniquely impacted by conflict and forced displacement (World Food Programme (WFP) et al., 2019). Conflict and displacement impact children in a number of ways including, and importantly, their education. Education can be severely affected by conflict in ways that include disruptions to schooling, lack of access to schooling, and lack of quality education, all of which can have life-long detrimental impacts for children (DeJong et al., 2017; Elsafti et al., 2016).

The association between education and wellbeing is comprehensively documented in the literature, with formal education well established as a critical social determinant of health (see, for example, Wilkins \& Marmot, 2003). Education has been linked to reducing poverty across generations, improving access to jobs, reducing infant mortality, and promoting greater health and wellbeing (Watkins \& Zyck, 2014). Education has also been associated with reducing experiences of marginalization and increasing one's sense of belonging in society, leading to improved mental health and wellbeing (Sirin \& Rogers-Sirin, 2015). The importance of education cannot be understated, and it is for these reasons that the United Nations declared education as a right of children in the 1989 Convention on the Rights of the Child (United Nations, 1989).

Barriers to safety, destruction of schools, and conversion of schools to shelters represent just some of the factors that contributed to disruptions in schooling for children in Syria (Sirin \& Rogers-Sirin, 2015). Following forced migration, children continue to face challenges in receiving education amid a context in which they are tasked with catching up on missed content resulting from disruptions in education and adjusting to a new environment (Sirin \& RogersSirin, 2015). 
The connection between education and quality of life points to the urgency of this issue. In recognition of this connection, education was made a priority for the Government of Lebanon and international and national organizations working with Syrian refugees. The "No Lost Generation" strategic framework presents just one of these initiatives. The framework was developed to respond to the Syrian and Iraq crisis and coordinates the work of governments, organizations, and communities in the region working to address education, child protection, and youth and adolescent programming under the same framework (No Lost Generation (NLG), 2018). However, despite initiatives such as this one, an overwhelmed and underserved sector leaves significant barriers for Syrian children to access quality education in Lebanon. Thus Lebanon faces an important challenge in ensuring that access to quality education is possible for Syrian refugee children to ensure that no generation is left behind.

This paper draws on findings from a 2016-2017 research study that explored the experiences of Syrian refugee families living in Lebanon. Education emerged as a prominent theme of the research. After providing an overview of the right to education in Syria and in Lebanon, the paper describes how Syrian families experience education in Lebanon and highlights barriers to education. Specifically, data on education revealed three main themes: (1) Syrian families greatly value education, (2) Syrian families consistently compare the education system in Lebanon with the education system in Syria, and (3) Syrian families identify multiple deficits in the Lebanese education system. Framed by education as a right, the paper concludes with suggestions for potential interventions to ensure that the right to education is upheld for displaced Syrian families living in Lebanon.

\section{Literature Review}

\section{The Right to Education in Syria}

Syria's commitment to education is evident from the past achievements of its education sector. Prior to the current conflict, Syria held a dominantly public education sector, which was publicly owned and funded through the Ministry of Education (Kabbani \& Salloum, 2010). Syria boasted universal enrolment of children in primary school, with near-universal records continuing through secondary school (Elsafti et al., 2016; Watkins \& Zyck, 2014). Syria also hosted a number of postsecondary academic institutions including research-based universities 
and technical institutions with industrial, commercial, and vocational streams (Baumbach, 2016). Public spending on the education sector increased through government reforms in the late 1990's to early 2000's, evening out after 2003 to account for $16 \%$ of total public funding (Kabbani \& Salloum, 2010). Syria contributes 5\% of its GDP towards the education sector. Both Syria's public spending and GDP contributions fall above the world average working to bring Syria on par with the world (Kabbani \& Salloum, 2010).

This account is in stark contrast to the realities of education amidst war. The conflict that followed resulted in significant changes to the availability of, and access to, education in Syria (Watkins \& Zyck, 2014). Attacks on schools and violence towards students and personnel is not uncommon amidst the conflict (NLG, 2018). Elsafti et al.'s (2016) study reported half of children enrolled in the study had no access to school. Internal displacement, lost community activities, overcrowded internally displaced camps, and destruction of schools further contributed to this stark shift, as compared to near-universal enrollment prior to 2011 (Elsafti et al., 2016). When war broke out in Syria in March 2011, many families were forced to put their children's education on hold in order to prioritize family survival. Education was an important factor affecting refugee families' decisions to leave their home country and resettle in host countries such as Lebanon (Metcalfe-Hough, 2015).

\section{The Right to Education in Lebanon}

Recognizing the significance of education to child development and wellbeing, the Lebanese education sector's response to the Syrian crisis has aimed to ensure that children have access to continuous quality education. The 2017-2020 Lebanon Crisis Response Plan outlines three priority areas: (1) increasing access to and demand for education, (2) increasing quality of education, and (3) strengthening the capacities of governmental and managerial bodies to deliver these goals and monitor progress (GoL \& UN, 2020). In light of this plan, the government has moved to waive or subsidize fees for vulnerable children in public schools and forgo the need to prove legal residency status in Lebanon as part of a 'Back to School' campaign launched in 2015 (DeHoop et al., 2019; GoL \& UN, 2020; Hamadeh, 2019; Karam et al., 2017).

Despite the education sector's commitment, conflict and ensuing displacement are known to disrupt children's right to learning. In the Lebanese case, there remain significant challenges in the response. Barriers to education can be grouped into two primary categories: system 
barriers and contextual barriers. Beginning with system barriers, the number of school-age children exceeds the capacity of the public school system in Lebanon (GoL \& UN, 2020). Therefore, education for Syrian refugees in Lebanon can currently be accessed through enrolment in Lebanese public schools or through alternative (non-formal) education pathways which include those managed by international organizations and nongovernmental organizations (NGOs) (Shuayb et al., 2014). Though some children have entered into the public school system, the majority have participated in informal learning systems including NGO provided programs and accelerated learning programs (Watkins \& Zyck, 2014). However, measures of the quality and efficacy of these programs are lacking in both the public and non-formal school systems. Non-formal education streams have been criticized for being inconsistent in their curriculum and inadequate in preparing children to continue their education beyond primary school (Karam et al., 2017). As well, often non-formal schooling systems are non-accredited and lack the certifications and educational documentation to allow children to prove their education level in order to continue schooling.

Primary school is compulsory and therefore consumes most of the focus of organizations working in the education sector. Pre-primary school for children aged three to five years and secondary school for children 15-18 years of age are underserviced and lacking within Lebanon, creating additional barriers to access and pointing to significant gaps in children's access to education (Hamadeh, 2019; Watkins \& Zyck, 2014). Only 13\% of children aged three to five years participate in early childhood education programs which are considered important for promoting wellbeing in young children (WFP et al., 2019; The Lancet, 2016). Though primary schools show higher enrollment records, these numbers decrease as children get older and enter secondary school (WFP et al., 2019). Children who are "not of school age" along with the related lack of services offered to particular age groups represent a well-reported barrier to education for Syrian children (WFP et al., 2017, p. 34).

Contributing further to the challenges of providing education in Lebanon is the geographical dispersion of Syrian families throughout Lebanon. A complex history of refugee migrations in Lebanon has encouraged the Lebanese government to enforce a "no-camp" policy within Lebanon (DeJong et al., 2017; Sanyal, 2017; Turner, 2015). As a result, there are no formal refugee camps within Lebanon. Syrian families live throughout all regions of Lebanon in settings that range from informal tented settlements, unfinished buildings, rented homes, and 
makeshift shelters including schools and warehouses (WFP et al., 2019). In this context, the experiences of Syrian families differ greatly in their challenges and access to services and supports such as education. Importantly, the geographic distribution of families is not in line with the distribution of schools throughout Lebanon (GoL \& UN, 2020; Watkins \& Zyck, 2014). As a result, rural and distant regions of Lebanon (such as areas of the Bekaa Valley) are often underserviced and contribute to record low enrolment in schools (GoL \& UN, 2020; WFP et al., 2019). The majority of children not enrolled in formal education live in remote areas where access to transportation can pose a challenge for reintroducing these children into the school system $(\mathrm{GoL}$ \& UN, 2020). In contrast, busy centers often face the challenge of having schools filled overcapacity without the resources or staff to address the needs of the population. In some cases, "second shift schools" (classes taught in the afternoons) have been created throughout Lebanon to address this challenge (Karam et al., 2017). However, this has led to the hiring of contract educators who have been criticized for being inexperienced and therefore unable to maintain the quality of education in these schools. In addition, much of educational resources in Lebanon have been directed to second-shift schools and non-formal education programming. The challenge with non-formal education is that it is minimally overseen by the global policy framework for refugee education (Karam et al., 2017). This means that decisions regarding the curriculum, instruction language, and educators is left to the NGO in charge, resulting in decisions that may not always be in line with education policies and standards (Karam et al., 2017).

Furthermore, the state of educational infrastructure in Lebanon represents another systemic barrier to quality education for children. The Ministry of Education and Higher Education has reported that over one-third of schools are in bad condition and require significant renovation to be able to sustain the large number of students (GoL \& UN, 2020). Schools have been accommodating larger numbers of students than usual, hosting Syrian, Palestinian, and Lebanese students, and operating with second shifts, leading to faster deterioration of the infrastructure. Lebanon would need to triple existing capacity in schools to be able to enroll all refugee children in the public school system (Karam et al., 2017).

As a response to these significant challenges in the education sector, in 2014, the Government of Lebanon, the UN, and other organizations developed a strategy aimed at ensuring all Syrian children receive education. Reaching All Children with Education (RACE) represented 
a joint effort to combat the challenges of the education sector (GoL \& UN, 2020; United Nations Educational, Scientific and Cultural Organization (UNESCO), 2016). RACE I (2014-2016) reported positive results including a significant increase in the enrolment of non-Lebanese children in public schools and the development of alternative education pathways for children unable to access public schools (GoL \& UN, 2017). Despite these accomplishments, challenges remain in ensuring all children have access to education. RACE II (2017-2020) was the second installment of the RACE strategy, operating in 2017-2020. The RACE II program outlined funding needs and tasks including investing in school infrastructure, improving the quality of education through training of teachers, and increasing the availability of schools (GoL \& UN, 2017; RACE, 2020). The project acknowledges that their goals are ambitious but achievable, requiring commitment from those in the education sector and the international community.

The education sector has reported modest contributions by donors to meet the needs to fulfill these goals. For example, of the $\$ 358$ million requested in 2016 , only $42 \%$ was provided (UNHCR, 2016). "Chronic under-financing” has been identified as a critical challenge for improving education within Lebanon (Watkins \& Zyck, 2014, p. 8), as is the case within many humanitarian emergency settings (Overseas Development Institute, 2016; Karam et al., 2017). Though the urgency of this issue has been recognized, symbolized by pledges and declarations by the international community, action beyond the recognition is lacking (Watkins \& Zyck, 2014). Watkins and Zyck (2014) have criticized the response of the international community writing, "Unfortunately, donor action has not matched the urgency implied by such declarations. Nowhere is the gap between rhetoric and action more evident than in education" (p. 2). They continue to write that “...unlike bombed-out buildings and columns of refugees, an 'education crisis' does not provide compelling media images. Yet failure to respond effectively to the education crisis will have profound consequences for the region's children now and throughout the coming decades" (Watkins \& Zyck, 2014, p. 2). Inconsistent and inadequate funding has significant effects on the ability of the Government of Lebanon, the UN, and partner organizations to maintain continuous quality education for children and expand schools and infrastructure (Karam et al., 2017). Gaps in educational services (e.g. early childhood education), geographical dispersion of families, and chronic underfunding of the education sector mark just some of the system barriers to education for Syrian children in Lebanon (GoL \& UN, 2017; Watkins \& Zyck, 2014). 
Barriers to education also involve contextual barriers that inhibit or discourage families from enrolling children in the education system. Despite the efforts of the education system, more than half of children remain unenrolled in schools signaling barriers that extend beyond the reach of the education sector (UNHCR, 2020). A primary barrier to education is the cost (WFP et al., 2019). It is estimated that $73 \%$ of Syrian families live below the poverty line, with $92 \%$ experiencing a level of food insecurity (with almost one-third severely or moderately food insecure) (GoL \& UN, 2020; WFP et al., 2019). Though the Government of Lebanon and the UN provide some support for schooling, covering the remaining costs in a context where families struggle to meet the necessities of life, is a difficult and often inhibiting barrier. Fifty-five percent of Syrians are extremely economically vulnerable, and poverty and economic precarity are known to incentivize children to engage in the labour market in order to make ends meet (Akesson \& Badawi, 2021; Carlier, 2018; GoL \& UN, 2017). This context which places children at risk of dangerous child labour and child marriage practices, coupled with insufficient funding to support students in the education sector, constitute significant barriers to education for children (GoL \& UN, 2020). The Government of Lebanon and the United Nations have recognized that these socioeconomic barriers require systemic change.

The Lebanon Crisis Response Plan has worked to improve access to education by addressing some of the contextual barriers that inhibit families through coordination of intersectoral strategies (GoL \& UN, 2017). For example, the School Feeding Programme (SFP) was established to increase and retain children in schools and to address drop-out rates. This program consisted of two components: a cash transfer program and a school snack program that provided children with healthy snacks in their classrooms. This strategy reportedly led not only to improved enrolment and retention, it improved food insecurity at the family level.

Other reported barriers include transportation to schools (Albakri \& Shibli, 2019). For families in distant and rural areas, transportation to and from schools can often be difficult to access or not within the financial capacity of families. Curriculum and language differences for Syrian children adapting to the Lebanese curriculum is another barrier (as children often require proficiency in French or English, not required in Syria) (Carlier, 2018; Karam et al., 2017; DeJong et al., 2017; Sirin \& Rogers-Sirin, 2015; UNICEF, 2012; Watkins \& Zyck, 2014). Differences in the Lebanese versus Syrian curricula create challenges for children transitioning to the education system and can sometimes result in children being placed in lower grades that 
they would have completed in Syria (GoL \& UN, 2017; Karam et al., 2017). Mistreatment, discrimination, and violence in schools represent another prohibitive barrier for families to enroll and send their children to school (Carlier, 2018; DeJong et al., 2017; GoL \& UN, 2020; Human Rights Watch (HRW), 2017; Karam et al., 2017; WFP et al., 2019). Many Syrian children have reported incidences of physical or verbal abuse in schools (DeJong et al., 2017; Sirin \& RogersSirin, 2015). Addressing this barrier has been recognized as an important component to any education sector strategy that aims to retain children in school (Carlier, 2018; DeJong et al., 2017; GoL \& UN, 2020; HRW, 2017; Karam et al., 2017; WFP et al., 2019). Legal restrictions represent another contextual barrier for Syrian families. Lack of legal status, inability to register in programs, and inability to verify previous education levels constitute key barriers for children looking to continue their education (GoL \& UN, 2017; UNICEF, 2012; Watkins \& Zyck, 2014).

Finally, it is important to note that although these barriers exist for all or most Syrian children, they are further compounded for children with disabilities (GoL \& UN, 2020). Barriers for children with disabilities include lack of inclusive facilities and trained educators who can foster learning for children with disabilities (GoL \& UN, 2017). Part of the strategy of the education sector for the years to come is to work on improving the inclusivity of children with disabilities in schooling through increased inclusive programming and curricula, professional development for personnel, and creation of inclusive schools. One current approach is the Ministry's Inclusive Schools Pilot in 30 schools that is providing data on how best to facilitate children with disabilities into the mainstream education sector (GoL \& UN, 2020). However, significant barriers remain that include the provision of qualified professionals and accessibility of schools that are not currently adjusted particularly for physical disabilities (GoL \& UN, 2020). The over-capacity of schools, again, poses a barrier and signals the desperate need for increased school infrastructure. These contextual barriers in the lives of Syrian families can act to restrict children's access to education.

Understanding barriers to education has significant implications for changing the education sector in Lebanon and improving access to and quality of education for Syrian children. More than half of Syrian children remain without access to education in Lebanon, highlighting the importance and urgent need for initiatives in this sector (Hamadeh, 2019). The voices of families and children who are directly impacted by education policies are critical to prioritizing education and creating programs and policies that are effective in meeting their 
needs. Therefore, this research highlights the perceptions and experiences of education for displaced Syrian families living in Lebanon using a comprehensive methodology described in the next section.

\section{Methodology}

Participants in this research project comprise families who had fled Syria and were "temporarily" resettled in three regions of Lebanon: northern Lebanon, Beirut, and the Bekaa Valley. In an effort to include multiple family members' voices in the research, at least three family members were invited to participate in the research: a young child (under the age of nine), his or her older sibling (age nine and above), and an adult caregiver (most commonly the father or mother). Inclusion criteria were based on family composition; in other words, only families with a child under the age of nine, with an older sibling between 9-18, and an adult caregiver were considered for the study. Different generations were represented in the research sample to better understand intergenerational experiences of war and displacement. The inclusion of all three family members in the research sample also supports the premise that caregivers - whether parents or older siblings - influence children's experiences. Even with the inclusion criteria outlined above, interviews often included members of the larger extended family with some interviews including up to 10 family members. The inclusion of extended family members provided a nuanced portrait of Syrian family’s experiences in Lebanon.

Basic demographics—gender, age, education, employment—were collected from each family member. Table 1 shows the distribution of the study sample according to age and gender. As described in Table 1, interviews were conducted with 44 families and a total of 351 individual family members, 100 adults and 251 children (48\% male and 52\% female). There were 312 family members who were from the primary index families ("nuclear" family or mother, father, children) and 39 family members who were part of the extended family (aunts, grandmothers, cousins, etc.).

Table 2 presents the distribution of the index families within the study sample according to education and employment. In nine of 44 families, only one or more parent had completed secondary school. Twenty-six of 44 households had one or more parent who was employed outside the home. In 15 of 44 households, both parents were unemployed. Only four of 44 households had index school-age children not attending school. 
Table 1: Family Demographics (Age \& Gender)

\begin{tabular}{|c|c|c|c|c|c|}
\hline & \multicolumn{2}{|c|}{ Index Family } & \multicolumn{2}{|c|}{ Extended Family } & Total \\
\hline \multirow{3}{*}{$\begin{array}{l}\text { Adults } \\
(18+)\end{array}$} & Male (father) & 36 & Male & 7 & 43 \\
\hline & $\begin{array}{l}\text { Female } \\
\text { (mother) }\end{array}$ & 44 & Female & 13 & 57 \\
\hline & \multicolumn{2}{|c|}{80} & \multicolumn{2}{|c|}{20} & 100 \\
\hline \multirow{3}{*}{$\begin{array}{l}\text { Children } \\
(<18)\end{array}$} & Male & 117 & Male & 9 & 126 \\
\hline & Female & 115 & Female & 10 & 125 \\
\hline & \multicolumn{2}{|c|}{232} & \multicolumn{2}{|c|}{19} & 251 \\
\hline Total & \multicolumn{2}{|c|}{312} & \multicolumn{2}{|c|}{39} & 351 \\
\hline
\end{tabular}

Table 2: Family Demographics (Education \& Employment)

\begin{tabular}{|l|c|c|c|c|}
\hline & \multicolumn{2}{|c|}{ Completed Secondary School } & \multicolumn{2}{c|}{ Employed Outside the Home } \\
\hline & Father & Mother & Father & Mother \\
\hline Yes & 6 & 5 & 24 & 2 \\
\hline No & 38 & 39 & 19 & 42 \\
\hline Total & $\mathbf{4 4}$ & $\mathbf{4 4}$ & $\mathbf{4 3}$ & $\mathbf{4 4}$ \\
\hline
\end{tabular}

The collaborative family interview was organized temporally, moving from discussions of life in Syria before the war, making the decision to leave Syria, the journey from Syria to Lebanon, life in Lebanon, and dreams for the future. Interviews used place-based methods that 
sought to understand the research participants' connections with their social and physical environments. In addition to being invited to speak during the collaborative family interview, children were asked to draw and make maps aligned with the family discussion. During the collaborative family interview, we provided time and space for the participants - both adults and children - to ask us questions about our backgrounds, our interest in this topic, as well as more specific questions about the research design and goals. We also asked participants for their feedback on certain questions and processes of the research design throughout the process.

At the end of the collaborative family interview, we invited the children to take us on a walk of their neighbourhood communities (with parental consent and child assent). During the neighbourhood walk, the children were asked to carry an activity logger, a small device that collects geographic position systems (GPS) data regarding physical movement. During the neighbourhood walk, children were encouraged to show us the places where, for example, they were allowed to visit, places where their daily activities occur, and places where people they know are located. Oftentimes, children would take the research team to their school or the area around the child's school. Throughout the course of the walk, the children had full control over the research process.

Following the neighbourhood walk, the research team asked three family members (one parent, one older child, and one younger child) to carry the activity logger for a period of one week. The GPS technology registered the family members' movements over the course of a typical week, thereby serving as an ethnographic mechanism by which to better understand their experiences. The maps created from the week-long activity logging often showed children's patterns of mobility to and from school. To aid in the recall, family members were asked to complete a simple diary of their daily activities while carrying the activity logger. The children's daily diaries often referred to their attendance at school.

At the end of the one week period, the research team re-visited the family for a follow-up interview. The family was asked to reflect upon their experiences over the past week and to share anything else that they did not get a chance to share during the first interview.

Participating families were not paid for their participation in the study. Materials used for the drawing and mapmaking (e.g., pens, pencils, markers, and paper) were left for each family at 
the end of the interview. However, families were provided with a small gift (e.g., a food basket, winter blankets, etc.) as a token of appreciation for their participation.

In addition to collaborative family interviews, two focus group discussions were held with Lebanese community workers and Syrian refugee outreach volunteers, as well as three semi-structured interviews with individuals who were working directly with Syrian families in Lebanon. The research also included elements of participant-observation of field agencies working with refugee families, attendance at meetings with aid organizations and local community-based organizations, as well as visits to informal settlements and other places in which refugee families were living. Finally, all members of the research team were invited to participate in a semi-structured debriefing interview to reflect upon their experiences and to provide recommendations for future research.

With the participants' permission, interviews were audio-recorded, translated, and transcribed prior to data analysis. Dedoose, an online research and data evaluation application, facilitated the data analysis. Data were analyzed through careful reading and collation of transcripts to ascertain meaning and significance that participants attributed to their experiences. In addition to the rich quantitative data gleaned from using GPS technology, qualitative transcripts were coded and concepts were generated and categorized into themes. The research data were rich and the findings were broad, covering topics such as family decision-making (Akesson \& Coupland, 2018b), family mobility (Akesson \& Coupland, 2018a), economic precarity (Akesson \& Badawi, 2021), health care (Sousa et al., 2020), and parenting (Akesson \& Sousa, 2020). This paper specifically focuses on the experience of education for Syrian families in Lebanon. The following section details the three findings related to education: (1) the high value of education, (2) how education in Lebanon is contrasted with education in Syria, and (3) families' perceived deficits of the Lebanese education system.

\section{Findings}

\section{Finding \#1: The High Value of Education for Syrian Families}

All families interviewed for this study placed a high value on education. According to the participating families, good education was something that parents wished that their children could attain in the near future, even amidst the many challenges they faced as a result of war and 
displacement. Parents often prioritized their children's education over their own needs. For example, 27-year-old mother of five, Umm-Ghani stated,

My dreams would all be fulfilled if my children just get an education. They are more important than everyone, than myself, and even my husband. So, having them get an education is all that I ask and hope for.

When asked about her future hopes and dreams, 37-year-old mother of nine, Umm-Adib answered, "I dream that my children continue their education. This is the only thing I think about." Similarly, 43-year-old father of five, Abu-Yousef, explained, "I am always concerned about the kids. I do not need any help. I only ask for my children. I am mostly concerned about their education."

Most of the GPS-tracked activity logging and the accompanying daily diaries noted movement to/from school or school as a central place in the lives of children and their families. For example, maps derived from the GPS-tracked activity logs showed children either at home or at school. Of the 34 families who completed the daily diaries, 29 families mentioned school. Despite many challenges facing these families, they still made education a priority. For example, the Abu-Nabil family that included 43-year-old Abu-Nabil, his wife 32-year-old Umm-Nabil, and their four children (ages 4 to 14) told the research team: "In Syria we were poor, and here in Lebanon, we are also poor." Nevertheless, all three of the school-aged children in the Abu-Nabil family attended school, including 10-year-old Nabil, who noted his attendance at school on his daily diary (see Figure 1). Despite highly valuing education, a family's precarious economic situation impacted their children's attendance at school. For some families in this study, for example, children did not attend school so they could work to support their family. This was especially true for families where the family was especially poor and/or the father was unable to work due lack of official residency. Some families reluctantly allowed their children to work instead of attend school, believing that their children were less likely to be arrested by Lebanese authorities for not having a residency permit. 
Appendix D: DAILY DIARY/ منكراتي التيومية

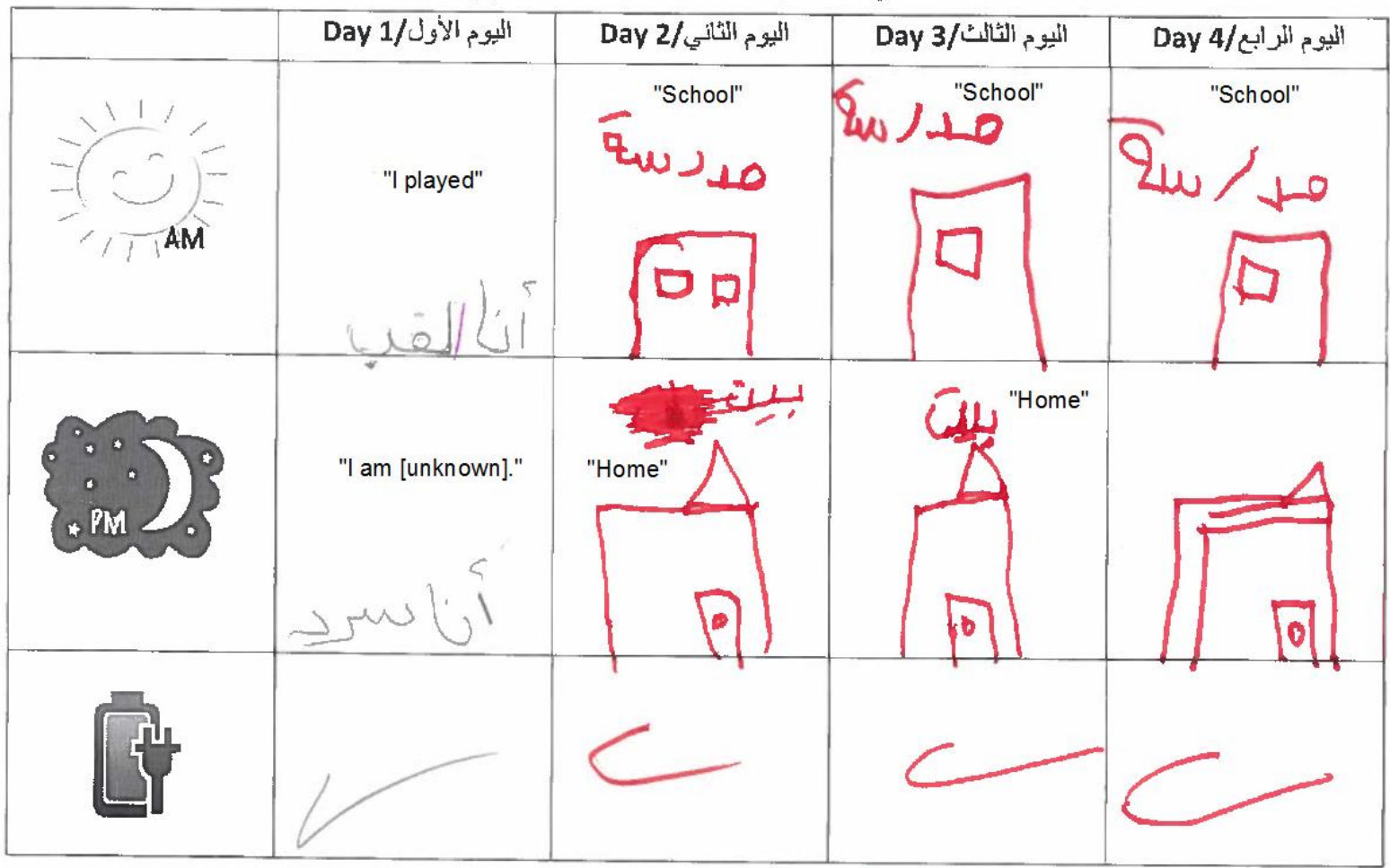

Figure 1. The first page of 10-year-old Nabil's daily diary. Note: The English translation is in quotation marks.

Whether a family's children were in or out of school, education featured in families' plans for the future and represented a source of hope amidst the difficulties they were experiencing. Parents tended to abandon their own individual dreams and focus their dreams on positive educational outcomes for their children. Some parents saw ensuring the education of their children as a sole priority in securing their children's futures. Forty-year-old father of five, Abu-Ibrahim, explained:

The most wonderful thing for the future is for the kids to get a good education. I like when they grow old and think, 'thank God for Mom and Dad, that they gave us a good education opportunity.'

Parents saw education as a means to a successful life with a good job. Like many parents, 37year-old Umm-Zahra's dream was that her two young daughters, who were currently not enrolled in school, would become educated and have "a good profession." The importance of education was especially apparent in Umm-Zahra's mobility map (see Figure 2) that showed her 
and her two daughters traveling the same route most days: leaving their apartment in the Bekaa Valley to travel to Umm-Zahra's continuing education classes. Figure one shows the routes taken by Umm-Zahra and her daughters over the course of one week, with the overlapping colours of Umm-Zahra in red and her daughters in purple and pink. Umm-Zahra explained that if her daughters were not in school then they would learn about the importance of education by accompanying her to her classes. Like Umm-Zahra, families saw education as an investment in their children's future to hopefully help them secure a positive future.

\section{The Umm-Zahra Family}

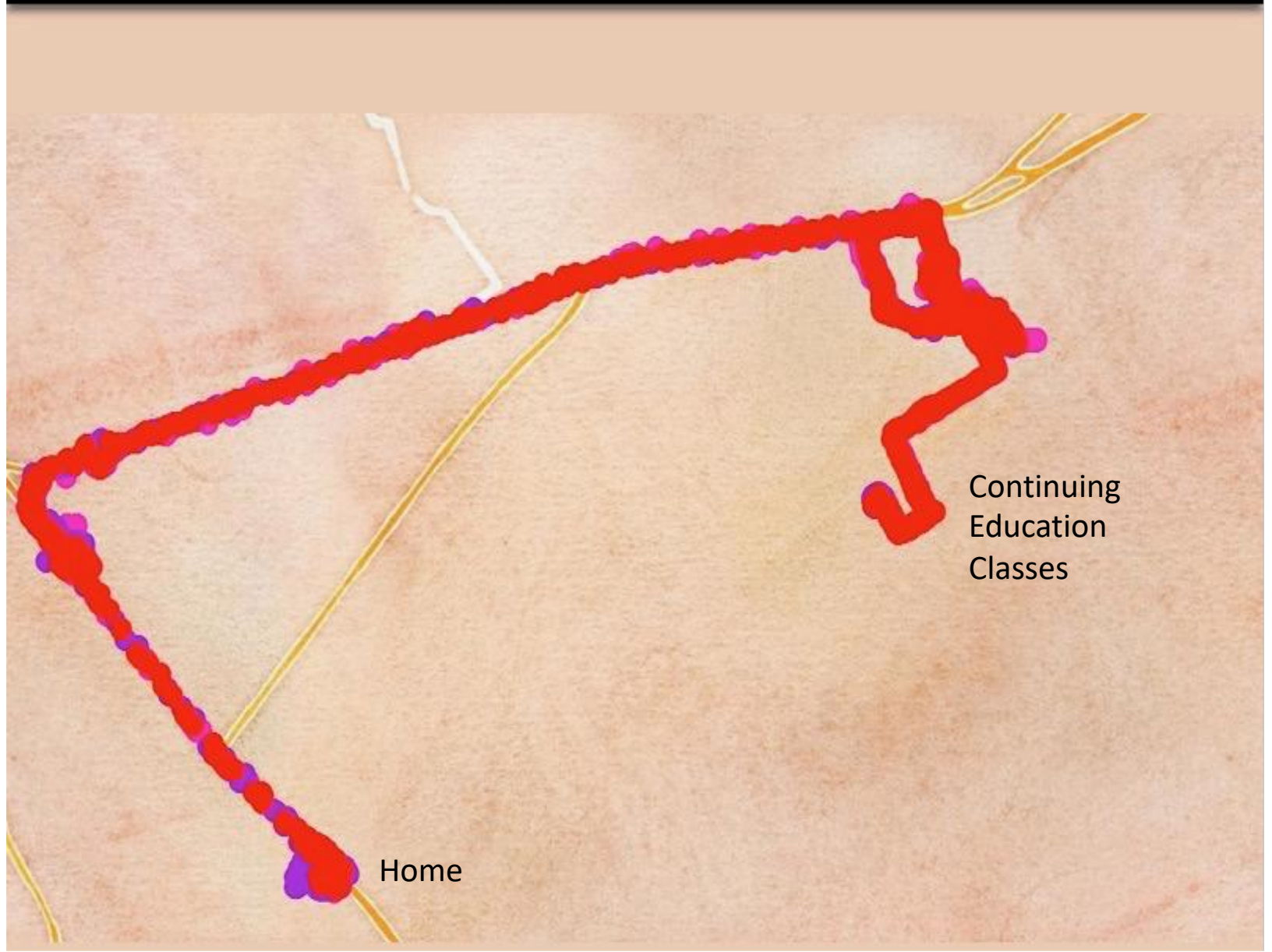

Figure 2. GPS-tracked mobility tracking of Umm-Zahra (red) and her two daughters (purple and pink). From: www.outofplaceresearch.com

The high value that Syrian families placed on education served as a major factor informing families' decisions to leave Syria and resettle in Lebanon. Families reflected on the 
decision-making process to leave Syria, describing harrowing experiences and difficult situations. For example, 63-year-old grandmother Umm-Jamal described how the terror wrought by Daesh (also known as Islamic State or ISIS) and the desire for education was one reason that her family decided to leave Syria:

The first thing that made us leave was the ruling of Daesh. They made us hate our country. They made us hate our house. We left on the basis that I'd come to Lebanon to provide the children with education.

In this example from Umm-Jamal, the presence of Daesh represented a push factor for the family, while the promise of education represented a pull factor in moving to Lebanon. Many families left Syria so that their children could resume their education and have a good future. For example, 34-year-old single mother six Umm-Layth described how resettlement in Lebanon had enabled her children to attend school thereby representing a positive future for her children:

That I see these children, that's it. And that they have a future. Their future is important, so that their education isn't for nothing. So they can have qualifications, get higher education, and get jobs.

Of course, most participating families would still rather be living in Syria than Lebanon, and often lamented the poor quality of the Lebanese education system in comparison to Syria. Their children and their children's futures kept them tethered to Lebanon, even though they preferred to return to Syria. As 32-year-old mother of six, Umm-Nour, explained, "If it was not for my children, I would run back to my country and my home, even if there were air strikes and attacks."

\section{Finding \#2: Education in Lebanon in Contrast to Education in Syria}

Families who have been forced to migrate to another country may have high expectations of the host nation that might not fit reality. In this case, Syrian families' positive experiences of education in Syria informed the expectations they had of the education sector in Lebanon, helping families to identify major gaps and challenges. This understanding of the past informing the present was related to elements of both nostalgia for their lost home of Syria, but also a sense of dignity that they deserve better circumstances than they are currently experiencing. In this section, families' views on education as compared with Syria are presented while the section on 
finding number three will describe the gaps and challenges in the Lebanese education sector that families identified.

Families overwhelmingly discussed their experiences with education by describing education in Syria prior to the war. Education in Syria was free for all children, with nearuniversal enrolment for both primary and secondary education (Menacere, 2010). The success of Syria's education system prior to the war was reflected in the high literacy rates, counting fourfifths of the Syrian population as literate. It is therefore not surprising that families in this study often described the deficits of the Lebanese education system in contrast to the strength of the Syrian education system. Forty-one year-old mother of five, Umm-Tariq, echoed a common refrain: "...even if there are schools here [in Lebanon], they are not the same as the ones in Syria." Similarly, 37-year-old father of seven, Abu-Farid described,

Living conditions in Syria are much better than here in Lebanon. Everything is very costly in Lebanon. For example in Syria there is free education and lots of services are not really expensive. In Lebanon the situation is quite different.... even though my kids are going to school here in Lebanon, you feel that this education is not really a good one...

Similarly, 37-year-old Umm-Zahra expressed frustration that she was able to get a good education in Syria before the war, but that her two young daughters do not have the same opportunity in Lebanon:

It doesn't make sense that I'm educated more than my child. It doesn't make sense to grow up [without education]. I can teach them how to write, read, some computer science, but I can't give them all the education and they should be in University somehow, this will be impossible if we stay in Lebanon.

The weakness of the Lebanese educational system compared with positive educational experiences in Syria before the war is heard in the words of 41-year-old mother of five, UmmTariq: "Sometimes you look at your children, and you think that it's not fair. It is such a shame that they had to leave school [in Syria].” Most families interviewed, therefore, preferred the education system in Syria, not only because of its accessibility in terms of cost, but because they believed that it had a stronger curriculum. Therefore, not being in Syria and the inability to 
access quality education for their children in Lebanon was a source of high stress for many families.

\section{Finding \#3: Syrian Families Perceptions of Deficits in the Lebanese Education System}

Families identified four main deficits with the education system for Syrian children in Lebanon: (1) control of education by the private sector, (2) weak curriculum, (3) violence in schools, and (4) inadequate proof of attendance. These challenges will be described in detail below.

\section{(1) Control of Education by the Private Sector}

There are not enough schools in Lebanon to meet the needs of the displaced Syrian population. Families described instances when their children were rejected from enrolling in public schools that should have been accessible to them. For example, 28-year-old mother of five, Umm-Rais explained, "education is our greatest concern, because we tried to admit our daughters to public schools but then they rejected them." Due to the overwhelming number of Syrian children in need of formal education and the strain this places on Lebanon's existing educational system, many unofficial, private-sector educational programs have begun operating in contradiction to government policy (Buckner et al., 2017). Approximately 70\% of Syrian children enrolled in school are in private programs (Shackle, 2017). There is a wide variance in the private programs available. Some of these private schools are considered to provide quality education. In fact, many families suggested that if they had the funds, they would send their children to these schools. For example, 50-year-old father of five, Abu-Tariq explained,

And the other schools, they would cost us. If I could afford it I would have sent them to private schools. I would have spent all of my fortune on their education. But I can't. It's a shame.

However, other families critiqued these private schools as inadequate for the needs of their children. This point will be discussed below as another deficit.

Economic precarity was identified as a major barrier for all participating families forcing families to prioritize needs (Akesson \& Badawi, 2021). For many families experiencing economic precarity, they had to prioritize children's work over their children's school 
attendance, for example, so the family could have enough to eat. Umm-Tariq explained, "if you want [a] good education, you have to pay for it." Nima, Abu-Tariq's sister, added, "if you have money, you can get anything." However, other schools may not utilize transparent systems of enrolment thereby leaving children without adequate education and a feeling of inequity. For example, 43-year-old father of five, Abu-Yousef, explained: “...the organizations are selectively helping the families. They are not helping everyone here in the camp. This is not fair." Furthermore, as Abu-Yousef describes, these schools are not certified: "What will happen when they want to pursue their higher education? The [NGO] schools here are not certified and the curriculum is very different."

\section{(2) Weak Curriculum}

The perception of the weakness of the Lebanese curriculum was a common refrain among Syrian families, and, as noted above, criticism was often couched in comparison to the education system in Syria. Families criticized the quality of the Lebanese curriculum noting multiple examples of deficit. Thirty-eight year-old father of five, Abu-Ammar, explained: "The curriculum that the Syrian children are being taught in Lebanon is very weak. A child here [in Lebanon] would go to school for two to three years and wouldn't be taught the alphabets." Echoing Abu-Ammar, Syrian families believed that this lack of quality put their children at a disadvantage. Families expressed the belief that if their children did not have a concrete educational foundation, they would not be able to excel academically. Nima, an aunt in the AbuTariq family, explained how the Lebanese curriculum is focused on French which can challenge Syrian children's learning:

[In Syria] kids start to learn French in the 5th grade. But here [in Lebanon], they start taking French from the first grade. And that's a little bit hard. And they don't learn enough Arabic words and letters. It's hard for the kids to catch up.

In fact, one of the most significant challenges for Syrian children in the Lebanese system has been the foreign language component (Carlier, 2018; Shackle, 2017).

Nima's comments underscore the challenges facing refugees and their host countries in terms of providing an adequate education for children who are coming from different educational systems. Many participants in this study chose Lebanon because of the shared history and cultural background. But systems such as education may be quite different. Seemingly small 
variations, such as which languages are taught in school and when they are taught, can contribute to families' perceptions that the curriculum is not adequate for their children.

\section{(3) Violence in Schools}

The third deficit that the research uncovered was violence within the schools. Despite a ban on violent discipline by Lebanon's Ministry of Education and Higher Education in 1974, corporal punishment and verbal humiliation are still a concern in Lebanon's education system (Bahou \& Zakharia, 2019). Historically, Lebanon's public school system has enrolled the poorest students, while families from higher socio-economic backgrounds can afford and attend private schools (Center for Educational Research and Development, 2012). Furthermore, the influx of large numbers of Syrian refugee families since 2011 has led to dramatic increases in enrollment in public schools (World Bank, 2018). The factors combined have greatly strained Lebanon's public education system.

During one of the neighbourhood walks, two brothers from Beirut showed the research team the area around their school. The researchers described how the boys are looked down upon because they are Syrian and are often mistreated by teachers, even though they are shy and quiet students. The mother later told the research team that the school administration condones this violence because the children "belong to the bulk" or are part of the Syrian refugee influx into Lebanon. One NGO worker identified the increased stress on the educational system, resulting specifically from overcrowded schools and overworked teachers, as contributing to increased instances of violence within the schools: "So, the whole school system-with the second shift schools...in place - are not really equipped. Teachers are overworked. They have a lot of violence within schools." This quote highlights how violence is expansive, encompassing not just direct violence from peers, teachers, and community members, but also structural violence in the form of discrimination and racism. Research from Akesson (2015), Bahou (2014, 2015), Sirin \& Rogers-Sirin (2015), and Shuayb, Makkouk, \& Tuttunji (2014) among others have identified violence in schools as a prohibitive barrier for families to enroll in and attend school.

\section{(4) Inadequate Proof of Attendance}

Many of the families interviewed for this project described the inadequate proof of school attendance for their children as a major deficit in the Lebanese education system. They noted that while religious and charity-funded schools allow Syrian children to enroll in their classes, they 
are not recognized by the Lebanese Ministry of Education. As such, they are not able to provide the children with official certificates upon their graduation. Without proof that they graduated from primary or secondary school, these children may encounter barriers to obtaining further education. Forty-two year-old mother of six, Umm-Karam explained:

I am scared for the education of my children. I know that they are now attending school, but it's not really adequate. After they finish they do not get any official certificates which prove that they have completed a certain level of classes. I think this will affect my children's education wherever we go. I do not want them to struggle getting in the classes that they should be in.

Thus, not only do the participating families see the effects of their displacement in Lebanon as affecting them in the present, they see the ripple effects of an inadequate educational system that can impact their children's long-term potential.

\section{Conclusions \& Implications}

The commitment of Syrian society to education carries on through all stages of the refugee experience, from flight to displacement and resettlement. It is not uncommon for refugees to find themselves resettled in a context where their academic achievements are not recognized, and they are unable to practice the careers they developed back home (AdamutiTrache, 2016). Influenced by this harsh reality, parents can place their dreams and values onto their children, becoming fierce advocates for their children's education and their family's future prosperity. This study supports the point that the value of education guides families in their decision-making in refugee settings, as the dream of a better future for their children achieved through higher education becomes vital.

The data suggest that education plays an important role in the lives of Syrian families, both in Syria before the war and in their current contexts of displacement in Lebanon, for their children's future hopes and dreams. Parents hope that by getting an education, their children will be able to successfully integrate into society and be able to earn a livelihood.

The families fondly remembered their experiences with education in Syria before the war, describing the accessibility and rigorousness of the curriculum. Comparing the education system in Syria before the war to the system currently in Lebanon became a source of stress for 
families, as their standards of education based on their experiences in Syria before the war were unmatched in their current circumstances. Furthermore, families' precarious economic status made it impossible for them to ensure that their children were able to access a better education.

The research findings also underscore that by being displaced and living in Lebanon, the families face a number of challenges in accessing and experiencing education. Lack of financial resources for many families is one factor that binds their children to NGO-controlled schools, which may not provide official documentation that will eventually grant children access to higher education. Additionally, the curriculum in these schools is considered to be weak by many Syrian parents, especially as parents compare it to their educational experiences in Syria. Violence in schools is another contributing factor that deprives Syrian children of a positive educational experience in Lebanon (Carlier, 2018; HRW, 2017). Findings indicate that transportation is a barrier for some families who send their children to school. Often for these families, transportation wasn't systemically or financially available for children, most often impacting children outside of Beirut. These factors contribute to inadequate access to education and lower attendance rates among Syrian children, and are a source of concern and stress for Syrian families.

The findings suggest multiple avenues for intervening at the levels of practice, policy, and research in order to ameliorate some of the challenges identified by the research participants. Although there is a need to improve the education infrastructure in Lebanon, the findings highlight the importance of ensuring the inclusion of Syrian refugee children in education in Lebanon. Exclusion represents a key barrier for families to enroll and ensure their children attend school, thereby decreasing attendance and increasing dropout rates (Shackle, 2017).

Programs could also aim to decrease or eliminate the financial barriers that families face in ensuring their children receive a good education. For families who are struggling to ensure they meet their families' basics for survival (e.g., food and shelter), education gets deprioritized. Children in these families may engage in labour practices that take priority over education even though parents acknowledge that education is an investment in their children's future work prospects (Halldorsson, 2017). This is yet another example of families being forced to make decisions based on their present difficulties rather than the potential for the future. Second shift schools have inadvertently addressed this issue, allowing some children to attend school while 
also working. While second shift schools have enabled Syrian children to attend without having to prove residency or pay school fees (GoL \& UN, 2017; Shackle, 2017), this kind of educational system also has its drawbacks. In the afternoon, educators may be exhausted from having already worked all day, but are faced with a new and energetic set of students eager to learn. Therefore, the quality of learning time may be compromised (Shackle, 2017). Furthermore, there is evidence that the second shift schools increasingly segregate Lebanese and Syrian children, which can lead to feelings of isolation and exclusion and impact community relations between the host community and refugees (International Alert, 2015).

Therefore, this research also points to some changes that could be made within schools themselves. There should be an increase in the number of trained and qualified teachers in both public and private schools, as well as specially-trained teachers for children with disabilities. Schools should have clear admissions policies aligned with ensuring accessibility and inclusivity, especially for children with disabilities. They should be mandated to provide up-to-date certification of students' educational records. However, in the face of meager human resources and funding shortfalls to assist in the education of Syrian refugee children (HRW, 2017; Watkins \& Zyck, 2014), all of these improvements might remain unaddressed.

An important matter of adhering to human rights provisions needs to be addressed while aligning the accessibility of education to the needs of refugee children. Though families never explicitly stated that education was a right, the importance that they placed on their children attaining a good education implies that families see education as being nearly as important as food and shelter. However, for some families struggling economically, older children were the first to be pulled out of school so they could work.

Article 19 of the Universal Declaration of Human Rights declares that "everyone has the right to freedom of opinion and expression", and "to seek, receive and impart information and ideas through any media and regardless of frontier' (Wofford \& Tibi, 2018, p. 182). In order for children to express themselves as well as gain access to educational media, adequate literacy is necessary. The United Nations Convention on the Rights of the Child (UNCRC, 1989) also states that all actions and primary considerations must be made in the best interests of the child. Access to education impacts child's wellbeing in varying ways. UNCRC Articles specify children's rights to 'attainable standard of health (Art. 24), survival and development of the child (Art.6), 
the right to rest and leisure (Art. 31), the right to a standard of living adequate for the child's development (Art. 27), and the right to education (Art. 28, 29) (Candappa, 2000). Barriers to adequate resources, infrastructure, inclusivity, and accessibility to education for Syrian refugees in Lebanon demonstrate that the criteria specified in the Convention on the Rights of the Child is not being met in Lebanon.

Finally, even though the educational experiences of families was a major theme in the larger research project, it was not the sole focus. Findings point to specific areas and methodologies that might be explored in future research focusing on education, specifically among displaced Syrian families in Lebanon and generally among displaced and resettled populations around the world. Within Lebanon, research should focus on a larger sample size of families to better ascertain the challenges within the educational system. Within such a study, the voices of teachers, as well as parents and students, should be included in order to paint a complete picture of the challenges and successes within the educational system. Also within the context of Lebanon, research should include both public schools and private, NGO-run schools, as the participants in the current study noted this was an area of important divergence in terms of access and quality.

In the context of displacement, Syrian families face challenges with the Lebanese education sector and refugee programs that often struggle to reach Syrian students. Yet, families demonstrate their unwavering commitment to education by continuing to challenge the systems in place as they navigate life amid displacement. 


\section{References}

Adamuti-Trache, M. (2016). Pursuing post-secondary education in the host country and the occupational attainment of highly educated immigrants to Canada. Journal of Education and Work, 29(2), 143-166.

Akesson, B. (2015). School as a place of violence and hope: Tensions of education in postintifada Palestine. International Journal of Educational Development, 41, 192-199. https://doi.org/doi:10.1016/j.ijedudev.2014.08.001

Akesson, B., \& Badawi, D. (2021). "My heart feels chained": The effects of economic precarity on Syrian refugee parents living in Lebanon. In C. W. Greenbaum, M. M. Haj-Yahia, \& C. Hamilton (Eds.), Handbook of political violence and children: Psychological effects, intervention and prevention policy (pp. 301-320). Oxford University Press.

Akesson, B., \& Badawi, D. (2019). Economic precaity among Syrian refugee families living in Lebanon: Policy recommendations to restore hope in the context of displacement (Issue XV; Policy Points). International Migration Research Centre. https://scholars.wlu.ca/imrc/40/

Akesson, B., \& Coupland, K. (2018a). Seeking safety, finding fear: Syrian families' experiences of (im)mobility and the implications for children's rights. Canadian Journal of Children's Rights, 5(1), 6-29.

Akesson, B., \& Coupland, K. (2018b). Without choice?: Understanding Syrian refugee families' decisions to flee. Interntional Organization for Migration (IOM) Migration Research Series, 54.

Akesson, B., \& Sousa, C. (2020). Parental suffering and resilience among recently displaced Syrian refugees in Lebanon. Journal of Child and Family Studies, 29, 1264-1273.

Albakri, T. Z., \& Shibli, R. (2019). How to improve sustainability: The critical role of education for Syrian refugees. Development in Practice, 29(5), 662-669. https://doi.org/10.1080/09614524.2019.1612323

Bahou, L. (2014). Student (dis)engagement in postwar Lebanon: Barriers and pathways in school learning [PhD Thesis]. University of Cambridge.

Bahou, L. (2015). Addressing issues of (in)justice in public schools within postwar Lebanon: Teachers' perspectives and practices. International Journal of Educational Development, 4(3), 363-376. 
Bahou, L., \& Zakharia, Z. (2019). “Maybe that's how they learned in the past, but we don't learn like this today": Youth perspectives on violent discipline in Lebanon's public schools. International Journal of Educational Development, 70. https://doi.org/10.1016/j.ijedudev.2019.102098

Baumbach, K. (2016). The education system in Syria: An overview. IEM Spotlight Newsletter, 13(2).

Buckner, E., Spencer, D., \& Cha, J. (2017). Between policy and practice: The education of Syrian refugees in Lebanon. Journal of Refugee Studies, 1-22.

Candappa, M. (2000). The right to education and an adequate standard of living: Refugee children in the UK. International Journal of Children's Rights, 8(3), 261-270.

Carlier, W. (2018). The widening educational gap for Syrian refugee children [Background report]. Kids Rights. https://reliefweb.int/sites/reliefweb.int/files/resources/Background\%20Report\%202018\% 20-

\%20The $\% 20$ Widening\%20Educational\%20Gap\%20for\%20Syrian\%20Refugee $\% 20$ Child ren_0.pdf

Center for Educational Research and Development (CERD). (2012). Statistical bulletin for the academic year (2011-2012). Author.

DeHoop, J., Morey, M., \& Seidenfeld, D. (2019). No lost generation: Supporting the school participation of displaced Syrian children in Lebanon. The Journal of Development Studies, 55(sup1), 107-127.

DeJong, J., Sbeity, F., Schlecht, J., Harfouche, M., Yamout, R., Fouad, F. M., Manohar, S., \& Robinson, C. (2017). Young lives disrupted: Gender and well-being among adolescent Syrian refugees in Lebanon. Conflict and Health, 11(1), 23. https://doi.org/10.1186/s13031-017-0128-7

Elsafti, A. M., van Berlaer, G., Al Safadi, M., Debacker, M., Buyl, R., Redwan, A., \& Hubloue, I. (2016). Children in the Syrian civil war: The familial, educational, and public health impact of ongoing violence. Disaster Medicine and Public Health Preparedness, 10(6), 874-882. https://doi.org/10.1017/dmp.2016.165 
Government of Lebanon (GoL), \& United Nations (UN). (2017). Lebanon Crisis Response Plan: 2017-2020. Authors. http://reliefweb.int/sites/reliefweb.int/files/resources/2017_2020_LCRP_ENG-1.pdf

Government of Lebanon (GoL), \& United Nations (UN). (2020). Lebanon crisis reponse plan: 2017-2020 (2020 update). Authors. https://data2.unhcr.org/en/documents/download/74641

Halldorsson, H. (2017). Syrian refugee children in Lebanon at risk of child labour, missing out on education. UNICEF Newsline. https://www.unicef.org/education/lebanon_94437.html

Hamadeh, S. (2019). A critical analysis of the Syrian refugee education policies in Lebanon using a policy analysis framework. Journal of Education Policy, 34(3), 374-393.

Human Rights Watch (HRW). (2017). Remove barriers to Syrian refugee education. HRW. https://www.hrw.org/news/2017/04/05/remove-barriers-syrian-refugee-education

International Alert. (2015). Better together: The impact of the schooling system of Lebanese and Syrian displaced pupils on social stability. Author. https://www.internationalalert.org/sites/default/files/Lebanon_LebaneseSyrianSchoolingSystem_EN_2015.pdf

Kabbani, N., \& Salloum, S. (2010). Financing higher education in Syria. In A. Galal \& T. Kanaan (Eds.), Financing higher education in Arab countries (pp. 103-116). The Economic Research Forum.

Karam, F. J., Monaghan, C., \& Toder, P. J. (2017). 'The students do not know why they are here': Education decision-making for Syrian refugees. Globalisation, Societies and Education, 15(4), 448-463.

Kelley, N. (2017). Responding to a refugee influx: Lessons from Lebanon. Journal on Migration and Human Security, 5(1), 82-104.

Menacere, K. (2010). Education in Syria. Open University. http://www.open.edu/openlearn/society/international-development/internationalstudies/education-syria

Metcalfe-Hough, V. (2015). The migration crisis? Facts, challenges and possible solutions. Overseas Development Institute.

No Lost Generation (NLG). (2018, April). We made a promise: Ensuring learning pathways and protection for Syrian children and youth. Supporting the Future of Syria and the Region. Brussels II Conference, Brussels, Belgium. 
https://www.nolostgeneration.org/sites/default/files/webform/contribute_a_resource_to_n lg/401/brussels-conference-education-report.compressed.pdf

Overseas Development Institute. (2016). Time to let go: Remaking humanitarian action for the modern era. Humanitarian Policy Group. https://www.odi.org/sites/odi.org.uk/files/resource-documents/10422.pdf

Reaching All Children With Education (RACE). (2020). RACE II. Retrieved from http://racepmulebanon.com/index.php/features-mainmenu-47/race2-article

Sanyal, R. (2017). A no-camp policy: Interrogating informal settlements in Lebanon. Geoforum, 84, 117-125.

Shackle, S. (2017). How the Lebanese school system is segregating refugees. IRIN News. https://www.irinnews.org/feature/2017/06/27/how-lebanese-school-system-segregatingrefugees

Shuayb, M., Makkouk, N., \& Tuttunji, S. (2014). Widening access to quality education for Syrian refugees: The role of private and NGO sectors in Lebanon. Centre for Lebanese Studies. http://www.lebanesestudies.com/wp-content/uploads/2014/09/Widening-Accessto-Quality-Education-for-Syrian-Refugees-the-role-private-and-NGO-sectors-inLebanon-.pdf

Sirin, S. R., \& Rogers-Sirin, L. (2015). The educational and mental health needs of Syrian refugee children. Migration Policy Institute.

Sousa, C., Akesson, B., \& Badawi, D. (2020). "Most importantly, I hope God keeps illness away from us": The context and challenges surrounding health for Syrian refugees in Lebanon. Global Public Health.

The Lancet. (2016). Advancing early childhood development: From science to scale [An executive summary for The Lancet's series]. The Lancet.

Turner, L. (2015). Explaining the (non-) encampment of Syrian refugees: Security, class and the labour market in Lebanon and Jordan. Mediterranean Politics, 20(3), 386-404.

UNICEF. (2012). Education rapid needs assessment for displaced Syrian children: In schools, community and safe spaces. UNICEF. https://data2.unhcr.org/en/documents/download/36499

United Nations. (1989). Convention on the rights of the child. United Nations. 
United Nations Educational, Scientific and Cultural Organization (UNESCO). (2016). Bridging learning gaps for youth: UNESCO regional education response strategy for the Syria crisis (2016-2017). UNESCO. http://unesdoc.unesco.org/images/0024/002443/244333e.pdf

United Nations High Commissioner for Refugees (UNHCR). (2016). 3RP regional refugee and resilience plan 2016-2017: Mid-year report. UNHCR. https://reliefweb.int/sites/reliefweb.int/files/resources/3RPMid-yearReportJune2016.pdf United Nations High Commissioner for Refugees (UNHCR). (2020, April 9). Syria regional refugee response. Operational Portal: Refugee Situations. https://data2.unhcr.org/en/situations/syria?id=251\&country=107\&region=73

Watkins, K., \& Zyck, S. A. (2014). Living on hope, hoping for education: The failed response to the Syrian refugee crisis. Overseas Development Institute. https://www.odi.org/publications/8829-living-hope-hoping-education-failed-responsesyrian-refugee-crisis

Wilkins, R., \& Marmot (Eds.). (2003). The social determinants of health: The solid facts (2nd.). World Health Organization (WHO).

Wofford, M. C., \& Tibi, S. (2018). A human right to literacy education: Implications for serving Syrian refugee children. International Journal of Speech-Language Pathology, 20(1), $182-190$.

World Bank. (2018). Lebanon-Education Public Expenditure Review 2017. World Bank. http://documents.worldbank.org.libproxy.wlu.ca/curated/en/513651529680033141/Leban on-Education-Public-Expenditure-Review-2017

World Food Programme (WFP), United Nations High Commissioner for Refugees (UNHCR), \& UNICEF. (2017). Vulnerability assessment of Syrian refugees in Lebanon: 2017 report. Authors.

World Food Programme (WFP), United Nations High Commissioner for Refugees (UNHCR), \& UNICEF. (2019). Vulnerability assessment of Syrian refugees in Lebanon: 2019 report. Authors. https://www.unhcr.org/lb/wp-content/uploads/sites/16/2019/12/VASyR2019.pdf 